\title{
Die UNESCO-Generalkonferenz in Belgrad und die Position der Schweiz. Einige Bemerkungen.
}

La Conférence générale de l'UNESCO à Belgrade et la position de la Suisse.

Quelques réfléxions.

Philippe Grandjean

\section{(2) OpenEdition}

Journals

Édition électronique

URL : http://journals.openedition.org/sjep/940

DOI : $10.4000 /$ sjep. 940

ISSN : 1663-9677

Éditeur

Institut de hautes études internationales et du développement

Édition imprimée

Date de publication : 1 janvier 1981

Pagination : 253-259

ISSN : $1660-5926$

Référence électronique

Philippe Grandjean, « Die UNESCO-Generalkonferenz in Belgrad und die Position der Schweiz. Einige Bemerkungen. », Schweizerisches Jahrbuch für Entwicklungspolitik [En ligne], 1 | 1981, mis en ligne le 28 mai 2013, consulté le 08 septembre 2020. URL : http://journals.openedition.org/sjep/940 ; DOI : https://doi.org/10.4000/sjep.940

Ce document a été généré automatiquement le 8 septembre 2020

(c) The Graduate Institute 


\section{Die UNESCO-Generalkonferenz in Belgrad und die Position der Schweiz. Einige Bemerkungen.}

La Conférence générale de l'UNESCO à Belgrade et la position de la Suisse. Quelques réfléxions.

Philippe Grandjean

\section{NOTE DE L'ÉDITEUR}

Zusammenfassung auf Deutsch. Volltext auf Französisch in Annuaire suisse de politique de développement: "La Conférence générale de l'UNESCO à Belgrade et la position de la Suisse. Quelques réfléxions.", http://aspd.revues.org/1094.

\section{RÉSUMÉS}

Die 21. UNESCO-Generalkonferenz beschloss u.a. die Errichtung einer Neuen Internationalen Informations- und Kommunikations- ordnung (NIIO).

Die Haltund der Schweiz entsprach der klassischen Haltung gegenüber den Medien. Ihre Bevorzugung konkreter Projekte entspricht der offiziellen Konzeption der Entwicklungszusammenarbeit. Der Mac Bride Bericht spricht aber von einer generellen Domination der Industrieländer im Bereich des Informationswesens. Das Schweizer Konzept verdeckt die Ungleichgewichte im Gegenwärtigen internationalen Informationssystem.

Die Absichten des Mac Bride Berichts und der Mediendeklaration von Belgrad sind für den 
westlichen Verleger und Journalisten nicht zu akzeptieren. Sie zeigen den grossen Gegensatz zwischen einem liberalen Informationswesen un einer davon abweichenden Informationsauffassung. Die Schweiz wird eine Presse und Informationsfreiheit, die sie für sich geschaffen hat, international nicht in Frage stellen wollen. Wenn sich die Schweiz aber gegen die NIIO wehrt, so vor allem, weil sie die dominierende Position gefährdet sieht. Wenn die dritte Welt eine ausgewogenere NIIO fordert, sieht die Schweiz die Gefahr einer Staatskontrolle über die Information.

Es stimmt zwar, dass, je zentralisierter eine Staatsmacht ist, desto kleiner ist der Spielraum der freien Presse. Man muss jedoch davon ausgehen, dass gerade die Entwicklungsländer oft nach diesem Modell organisiert sind. Unsere Sieht der Medien wäre international jener, welche in den Entwicklungsländern verherrscht, an zupassen. Die Schweiz ist aber nur bereit, Infrastrukturverbesserungen im Informationswesen vorzunehmen, nicht aber, die Spielregeln zu ändern. 